\title{
COMPACTAÇÃo DE UM CAMBISSOLO HÁPLICO CAUSADA PELA EXTRAÇÃo FLORESTAL COM TRATOR SKIDDER
}

José Carlos Pezzoni Filho'*, Paulo Torres Fenner ${ }^{1}$, Kléber Pereira Lanças ${ }^{1}$ Diogo Pezzoni², Willian Bucker Moraes ${ }^{1}$, Haroldo Antunes Chagas ${ }^{1}$, João Cláudio Ribeiro Trosdorf ${ }^{1}$

*Autor para correspondência: jpezzoni@gmail.com

RESUMO: A compactação devido ao tráfego de maquinários ocasiona danos ao solo que podem interferir no adequado desenvolvimento do sistema radicular das plantas, apresentando como principal dano a diminuição da produtividade das culturas. $\mathrm{O}$ objetivo deste trabalho foi avaliar a compactação do Cambissolo Háplico ocasionada pelo tráfego do Skidder na extração de Pinus elliottii var. elliottii em ramal secundário de extração de madeira, nos rastros dos pneus e dos fustes, variando-se a frequência de tráfego do trator. Os rastros dos pneus e dos fustes foram na mesma linha de tráfego da passada anterior, cada qual localizado em seu respectivo rastro. A área de estudo localizou-se no município de Capão Bonito-SP, em cultivo de Pinus elliottii var. elliottii, e os dados de compactação foram obtidos da área sem tráfego (testemunha) e dos tratamentos com 1, 2, 3, 4 e 5 passadas do Skidder, em duas camadas, de 0,00-0,05 $\mathrm{m}$ e de 0,10-0,15 m de profundidade. Os resultados demonstraram que houve compactação adicional sob tráfego de cada passada do Skidder, sendo maior na camada de 0,00-0,05 m de profundidade. Adicionalmente, a compactação do solo foi mais acentuada sob menores teores de água no solo, sendo contrário ao esperado.

Palavras-chave: rastro, tráfego, passada, teor de água.

\section{COMPACTION OF AN INCEPTISOL CAUSED BY FOREST EXTRACTION WITH SKIDDER}

\begin{abstract}
The compaction due to machinery traffic causes damage to the soil that can interfere with the development of the root system of plants, resulting in decreased crop yields. The objective of this study was to evaluate the Inceptisol compaction caused by Skidder traffic in extraction of Pinus elliottii var. elliottii in secondary extension logging in tire tracks and stems, varying the frequency of tractor traffic. The tire tracks and stems were in the same line of traffic passage earlier, each located in their respective tracks. The study area was located in the municipality of Capão Bonito-SP, in cultivation of Pinus elliottii var. elliottii and samples were obtained from an area without traffic (control) and applications with 1, 2, 3, 4 and 5 Skidder passes in two layers, 0.00 to 0.05 and 0.10 $0.15 \mathrm{~m}$ depth. The results showed that there was additional compaction by each passage of the Skidder, being higher in the layer of 0.00 to $0.05 \mathrm{~m}$ depth. Soil compaction was more pronounced under lower water content in the soil, being contrary to the expected.
\end{abstract}

Keywords: track, traffic, past, water content.

\section{INTRODUÇÃO}

As causas das alterações na densidade do solo podem ser naturais, sendo difíceis de serem avaliadas e de ação lenta no solo como, por exemplo, a eluviação de argilas, ou artificiais, realizada por forças mecânicas originadas da pressão causada pelo tráfego de máquinas e ação de implementos sobre o solo (SECCO et al., 2004). Para Reichert et al. (2007), a compactação é por ação antrópica e o adensamento é um fenômeno natural.

O tráfego intensivo de máquinas tem sido o principal responsável pelo aumento da densidade e resistência mecânica do solo, diminuição da porosidade e condutividade hidráulica (HANZA; ANDERSON, 2005; SUZUKI et al., 2007), resultando na compactação do solo e alterando o meio onde o sistema radicular se desenvolve (MARCHÃO et al., 2007). Essas alterações repercutem negativamente no processo de troca gasosa do solo (KAISER et al., 2009).

A compactação pode reduzir a infiltração e a distribuição de água, além de dificultar a penetração das raízes no perfil do solo, podendo limitar a absorção de nutrientes pelas plantas (SUZUKI et al., 2008), o que prejudica o crescimento radicular das plantas (KAISER

1 Universidade Estadual Paulista - Botucatu, São Paulo, Brasil

2 Universidade Estadual do Mato Grosso do Sul - Cassilândia, Mato Grosso do Sul, Brasil

Cerne, Lavras, v. 20, n. 2, p. 199-208, abr./jun. 2014 
et al., 2009). Todos estes fatores ocasionam a redução da produtividade das culturas (REICHERT et al., 2009) e a qualidade ambiental em razão do aumento do processo erosivo (KRÜMMELBEIN et al., 2008).

Reichert et al. (2010) citam que as pressões aplicadas sobre a superfície do solo são distribuídas ao longo do perfil, em função das tensões e das deformações, em maior ou menor escala, de acordo com as características físicas do solo. Reichert et al. (2007) citam que em áreas agrícolas, a compactação ocorre até os $0,20 \mathrm{~m}$ de profundidade e em áreas florestais atinge maiores profundidades.

A carga que as máquinas transportam pode aplicar pressões aos solos maiores do que a sua capacidade de suporte de carga, resultando na compactação (DIAS JUNIOR et al., 2005), sendo que a umidade afeta diretamente a capacidade de suporte do solo ao tráfego (DIAS JÚNIOR et al., 2004). Nas condições de consistência plástica do solo, provocam deformação e compactação, que se traduzem em aumento da densidade do solo, como resultado da redução da porosidade total, especialmente da macroporosidade (MORAES et al., 2011).

Para o desempenho adequado dos maquinários na realização das operações agrícolas e florestais, o solo precisa estar com umidade adequada para o tráfego, porém, o teor de água que ocasionará maior incremento da compactação será diferente para cada classe de solo. Reichert et al. (2010) citam que a umidade é o principal fator que governa a quantidade de deformação que poderá ocorrer no solo no momento da realização das operações, e assim a compactação será máxima quando a umidade do solo for crítica para esse processo.

O manejo da cultura tem que ser realizado de forma planejada para causar uma menor compactação ao solo, sem ficar acima do limite prejudicial ao crescimento das culturas. Ocorrendo compactação superior ao limite, a produtividade da cultura será prejudicada, conforme foi constatado por Lockaby e Vidrine (1984), reduções no crescimento em altura de uma floresta de Pinus taeda, variando entre 40 e $60 \%$, apesar da compactação do solo ter se restringido unicamente aos $0,05 \mathrm{~m}$ próximos à superfície. Para tráfego contínuo em um mesmo local, Seixas e Souza (2007) verificaram que $80 \%$ do incremento da compactação de um solo ocorreu após as cinco primeiras passadas de um forwarder, demonstrando que o tráfego na área tem que ser bem planejado.

Este estudo avaliou a compactação do Cambissolo Háplico ocasionada pelo tráfego do Skidder na extração de Pinus elliottii var. elliottii em ramal secundário de extração de madeira, nos rastros dos pneus e dos fustes, variando-se a freqüência de tráfego do trator.

\section{MATERIAL E MÉTODOS}

O estudo foi desenvolvido em área localizada nas coordenadas geográficas de $24^{\circ} 13^{\prime} 43,8^{\prime \prime} \mathrm{S}$ e $48^{\circ} 17^{\prime} 33,8^{\prime \prime}$ W e altitude de 823 metros no Estado de São Paulo. O solo da região é classificado como Cambissolo Háplico Distrófico A moderado textura argilosa (EMPRESA BRASILEIRA DE PESQUISA AGROPECUÁRIA - EMBRAPA, 2006; INSTITUTO DE PESQUISAS TECNOLÓGICAS DO ESTADO DE SÃO PAULO - IPT, 1981). Segundo Köppen, a região apresenta clima Cfb, sem ocorrência de estiagem, com precipitação variando de 1100 a $2000 \mathrm{~mm}$, caracterizando como clima de região serrana (VENTURA, 1964).

A espécie florestal extraída foi o Pinus elliotti var. elliotti, oriunda de um povoamento florestal com 36 anos. A marca do Skidder utilizado era Caterpillar, modelo Cat 545 C, peso total de 19,2 t, com pneus utilizados da marca Foresty special - crc, Fyrestone - 35.5L32 - 16 lonas. Para cada passada foi utilizada uma carga diferente, sendo que a massa das 5 cargas foram 2,08; 2,79; 3,23; 4,22 e 2,39 toneladas para as $1^{\mathrm{a}}, 2^{\mathrm{a}}, 3^{\mathrm{a}}, 4^{\mathrm{a}}$ e $5^{\mathrm{a}}$ passadas, respectivamente. Estas cargas foram calculadas por meio da densidade da madeira, estimados com as amostras de discos dos fustes arrastados durante o experimento.

Para o cálculo da densidade da madeira foi utilizado o método do máximo teor de umidade, com 60 discos de madeira coletados de 12 fustes arrastados na área experimental, com espessura média de $0,05 \mathrm{~m}$ e diâmetros variados, a $0 ; 25 ; 50 ; 75 ; 100 \%$ da altura de cada fuste, conforme metodologia de Pereira et al. (1986).

No local do experimento, a máquina de esteira, modelo CAT D-6 com peso aproximado de 13 toneladas, realizou o corte do nível natural do terreno para abertura do ramal secundário de extração de madeira, desta forma a altura média do barranco foi de 1,80 metro. Isto ocorre devido a região apresentar relevo ondulado e para a extração das árvores é realizada a abertura de ramais secundários que em certos locais parecem estradas. As amostras da testemunha e $1^{\text {a }}$ passada foram coletadas no dia $02 / 02,2^{\mathrm{a}}$ e $3^{\mathrm{a}}$ passadas dia $03 / 02,4^{\mathrm{a}}$ e $5^{\mathrm{a}}$ passadas no dia $04 / 02$ de 2010 .

As amostras foram coletadas, em um mesmo ponto, nas camadas de 0,00 a 0,05 e 0,10 a $0,15 \mathrm{~m}$ de profundidade em relação ao nível do solo nos rastros dos pneus e dos

Cerne, Lavras, v. 20, n. 2, p. 199-208, abr./jun. 2014 
fustes. Os espaçamentos entre as amostras foram de 1,10 metro, sendo que nas subparcelas foram 5 pontos de coletas de amostras, onde cada subparcela era de 5,50 metros de comprimento. Para a primeira e última subparcela considerou-se 0,55 metro a mais para manter o padrão do espaçamento entre subparcelas, totalizando 34,1 metros de comprimento da área experimental. Entre as amostras dos dois tipos de rastros, o espaçamento médio foi de 1,31 metro, devido à distância entre os pneus do mesmo eixo serem de 2,32 metros, pois os fustes eram arrastados pela pinça do Skidder e entre os rodados traseiros (Figura 1).

Para a determinação da densidade do solo utilizouse o método do Anel Volumétrico (EMBRAPA, 1997). A equação utilizada para o cálculo da densidade do solo foi a seguinte:

$$
\begin{aligned}
& \text { Ds }=\mathrm{Ms} / \mathrm{V} \\
& \text { onde: } \\
& \text { Ds - densidade do solo }\left(\mathrm{Mg} \mathrm{m}^{-3}\right) \text {; } \\
& \text { Ms - massa da amostra seca a } 105^{\circ} \mathrm{C}(\mathrm{Mg}) \\
& \text { V - volume do anel volumétrico }\left(\mathrm{m}^{3}\right) .
\end{aligned}
$$

Para o cálculo do teor de água foram coletadas oito amostras em cada parcela, localizados em quatro pontos amostrais, onde em cada ponto amostral foram duas amostras de solo nas camadas de 0,00 a 0,10 e 0,10 a $0,20 \mathrm{~m}$ de profundidade. No rastro dos pneus foram coletadas quatro amostras em dois pontos amostrais, nas duas camadas citadas anteriormente, e para o rastro dos fustes a metodologia utilizada foi a mesma. O espaçamento entre as amostras foram de 2 metros dentro da parcela e subparcela. Cada rastro foi considerado uma subparcela, sendo coletadas duas amostras para cada camada (quatro amostras nas duas camadas). Essas amostras foram coletadas simultaneamente com as amostras indeformadas de solo, após cada passagem do Skidder na área experimental (Figura 1). Determinou-se o teor de água do solo no momento da coleta de solo de acordo com EMBRAPA (1997). O cálculo do teor de água (umidade gravimétrica atual do solo) foi de acordo com a equação 2 .

onde:

$$
\mathrm{U}=100(\mathrm{M}-\mathrm{Ms}) / \mathrm{Ms}
$$

$$
\begin{aligned}
& \mathrm{U}=\text { umidade gravimétrica atual do solo } \\
& \mathrm{M} \text { - massa da amostra úmida }(\mathrm{g}) \\
& \mathrm{Ms} \text { - massa da amostra seca }(\mathrm{g}) \text {. }
\end{aligned}
$$

Para a obtenção da curva de compactação do solo, compactou-se cinco corpos de prova, com umidades crescentes. A compactação dos corpos de prova se deu em três camadas, as quais receberam 25 golpes do martelo usado no ensaio de Proctor normal (STANCATI et al., 1981), determinando-se, a seguir, a densidade do solo. No ponto máximo da função ( $\mathrm{Ds}=\mathrm{aU} 2+\mathrm{bU}+\mathrm{c}$ ) obteve-se a densidade do solo máxima e a umidade ótima (péssima) de compactação (IEZZI et al., 1978), representadas nas expressões 3 e 4 :

Uót $=-b / 2 \mathrm{a}$

Dsmáx $=-\left(b^{2}-4 a c\right) / 4 a$

onde:

Dsmáx - densidade do solo máxima;

Uót - umidade ótima de compactação;

a, b, c - são os coeficientes de ajustes das equações.

No experimento foram utilizados seis tratamentos (sem tráfego e 1 a 5 passadas do Skidder na mesma linha de tráfego dos rastros). Para os seis tratamentos foram utilizados 6 parcelas, passando primeiro na parcela 1 até a parcela 6 , sendo que as parcelas 1, 2, 3, 4, 5 e 6 foram onde coletou-se as amostras de solo da testemunha e passadas $1,2,3,4$ e 5, respectivamente. Porém, antes da passagem do Skidder na parcela da testemunha, foram retiradas as amostras de solo para a quantificação do adensamento natural presente no local. Para cada tratamento, o Skidder trafegou no sentido do aclive do terreno, sendo esse com declividade média de $7 \%$. Os tratamentos adotados foram: área do experimento sem tráfego do Skidder; Passada 1 (1 passada do Skidder); Passada 2 (2 passadas do Skidder); Passada 3 (3 passadas do Skidder); Passada 4 (4 passadas do Skidder); Passada 5 (5 passadas do Skidder na área experimental) (Figura 1).

O delineamento estatístico utilizado no experimento foi o inteiramente casualizado. Cada parcela foi composta pela interação tripla entre os dois rastros (pneus e fustes) e duas camadas ( 0,00 a 0,05 e 0,10 a $0,15 \mathrm{~m})$; e as subparcelas foi resultado da interação dupla entre as duas camadas de cada rastro $(0,00$ a 0,05 e 0,10 a $0,15 \mathrm{~m})$. Em cada parcela foram retiradas 20 amostras nos rastros dos pneus e dos fustes (2 tipos de rastros - pneus e fustes, sendo 10 amostras para cada tipo de rastro). Dentro de cada subparcela, coletou-se 10 amostras nas duas profundidades, ou seja, cinco amostras (cada amostra foi uma repetição) de 0,00 0,05 m e cinco amostras de 0,10-0,15 m (Figura 1).

Por terem sido coletadas amostras nos dois rastros e em duas camadas, considerou-se a parcela como subsubdividida com duas interações de dados. Estas duas interações ( 2 tipos de rastros e 2 camadas de profundidades) dentro das parcelas foram coletadas nas 5 passadas do

Cerne, Lavras, v. 20, n. 2, p. 199-208, abr./jun. 2014 


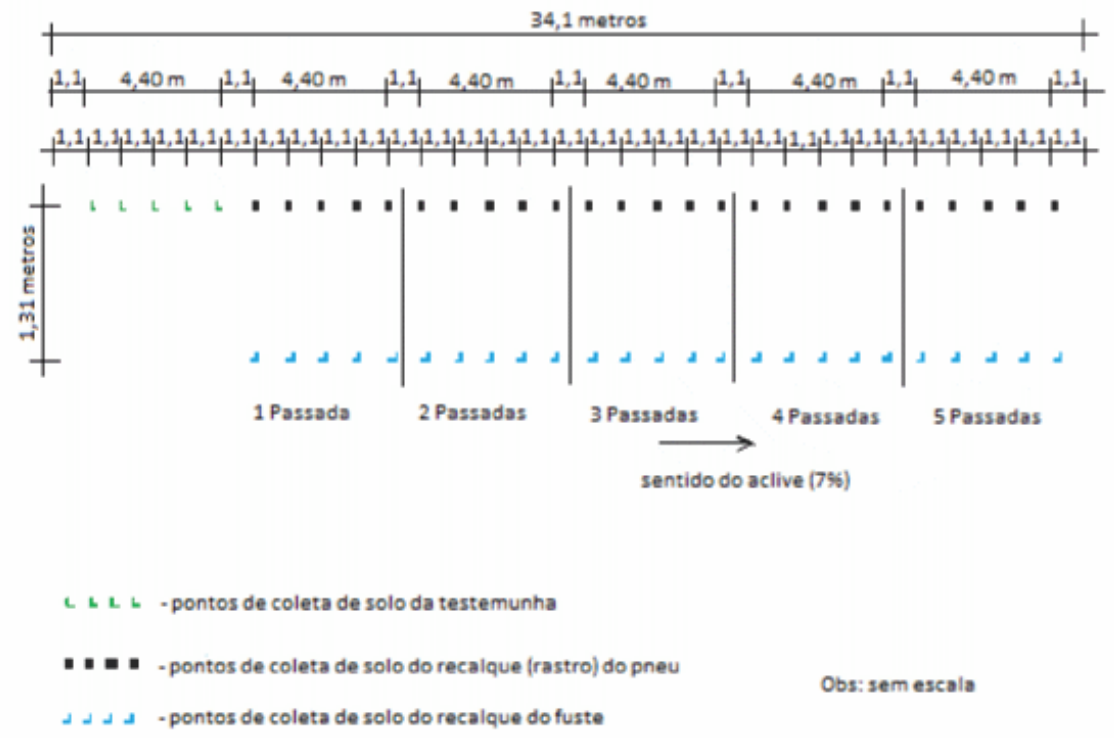

Figura 1 - Croqui da área experimental.

Figure 1 - Sketch of the experimental area.

Skidder, e para a testemunha coletou-se somente para a interação das 2 profundidades.

As médias de densidades do solo nos dois rastros e nas duas camadas foram avaliadas em conjunto, avaliandose interações triplas e duplas a $5 \%$ de probabilidade pelo teste de Tukey. Os resultados foram submetidos a análise de variância, com desdobramento das somas de quadrado dos efeitos em regressão linear simples e teste de médias pelo teste de Tukey ao nível de significância de 5\% de probabilidade.

\section{RESULTADOS E DISCUSSÃO}

As interações entre os dados dos dois tipos de rastros, repetições e rastros, e rastros e camadas; e as interações triplas entre repetições, rastros e tratamentos; e rastros, camadas e profundidades não foram significativos pelo teste de Tukey a 5\% de probabilidade devido aos valores encontrados serem iguais, estatisticamente, entre as diferentes variáveis. As interações significativas, ou seja, que apresentaram diferença estatística pelo mesmo teste, foram aquelas entre repetições; passadas; rastros e passadas; camadas; e passadas e camadas (Tabela 1).

$\mathrm{Na}$ Tabela 1 estão apresentados os dados da interação entre os rastros e as passadas (tratamentos) onde ocorreu diferença significativa a $5 \%$ de probabilidade pelo teste de Tukey. Para a passada 5, o rastro dos pneus apresentou uma menor compactação (1,34 Mg. m ${ }^{-3}$; Figura 2) quando comparado com o dos fustes $\left(1,38 \mathrm{Mg} \mathrm{m}^{-3}\right.$; Figura 4) sendo explicado pelo fato de haver menor área de contato do fuste com o solo.

Devido ao fato de o pneu apresentar uma maior área de contato com o solo, em relação ao fuste, ocorre melhor distribuição do peso da máquina sobre o solo. Para minimizar a compactação ocasionada pelos pneus, uma medida que pode ser adotada para o manejo com redução dos danos na extração florestal é citada por Andrade et al. (2000) que é a utilização de pneus florestais, pois aumentam a área de contato com o solo, minimizando a compactação do solo. $\mathrm{Na}$ interação entre as passadas e as camadas de $0,00-0,05$ e $0,10-0,15 \mathrm{~m}$, nas quais foram analisadas a compactação do solo por passada, ocorreu diferença significativa, bem como para a variável camadas (Tabela 1).

A camada superficial do Cambissolo Háplico, entre 0,00 e $0,05 \mathrm{~m}$ de profundidade, sofreu maior influência do tráfego do Skidder e do arraste dos fustes, sendo demonstrado na Tabela 2. Nesta tabela, foi realizada a análise comparativa das médias de densidades do solo, nos dois rastros e nas

Cerne, Lavras, v. 20, n. 2, p. 199-208, abr./jun. 2014 
duas camadas estudadas, obtendo-se os valores de 1,30 e $1,22 \mathrm{Mg} \cdot \mathrm{m}^{-3}$ nas camadas de 0,00 a 0,05 e 0,10 a $0,15 \mathrm{~m}$, respectivamente. A média de cada camada foi realizada com a utilização dos valores encontrados para os dois rastros (dos pneus e dos fustes) em suas respectivas camadas, sendo utilizados 10 valores de densidades do solo para o cálculo da média de cada camada. A maior compactação observada na camada de 0,00 a $0,05 \mathrm{~m}$ concordam com Silva et al. (2003), onde encontraram maiores valores de pressão de pré-consolidação na camada de $0,00-0,05 \mathrm{~m}$ em experimento com trator de massa total e lastro de 7,3 toneladas, em um Latossolo Vermelho distrófico.

Tabela 1 - Análise de variância das interações entre as médias de dados dos rastros dos pneus e dos fustes, da testemunha e passadas, e das duas camadas estudadas.

Table 1 - Analysis of variance of the interactions between the mean data from the tracks of tires and stems, the control area and the area of passes, and the two layers studied.

\begin{tabular}{lccccc}
\hline \multicolumn{1}{c}{ Variáveis } & GL & SQ & QM & F & Pr $>$ F \\
\hline rastros (rast.) & 1 & 0,00630750 & 0,00630750 & 10,40 & $0,0023^{\mathrm{NS}}$ \\
repetições (rep.) & 4 & 0,02475500 & 0,00618875 & 10,21 & $<0,0005^{*}$ \\
rep. X rast. & 4 & 0,00113833 & 0,00028458 & 0,47 & $0,7579^{\mathrm{NS}}$ \\
passadas (pas.) & 5 & 0,41245417 & 0,08249083 & 136,07 & $<0,0005^{*}$ \\
rast. X pas. & 5 & 0,04182750 & 0,00836550 & 13,80 & $<0,0005^{*}$ \\
rep. X rast. X pas. & 40 & 0,02132667 & 0,00053317 & 0,88 & $0,6597^{\mathrm{NS}}$ \\
camadas (cam.) & 1 & 0,18802083 & 0,18802083 & 310,14 & $<0,0005^{*}$ \\
rast. X cam. & 1 & 0,00080083 & 0,00080083 & 1,32 & $0,2561^{\mathrm{NS}}$ \\
pas. X cam. & 5 & 0,03095417 & 0,00619083 & 10,21 & $<0,0005^{*}$ \\
rast. X cam. X prof. & 5 & 0,00677417 & 0,00135483 & 2,23 & $0,0659^{\mathrm{NS}}$ \\
Resíduo & 48 & 0,0291 & 0,00060625 & & \\
CV(\%) & 1,96 & & & & \\
\hline
\end{tabular}

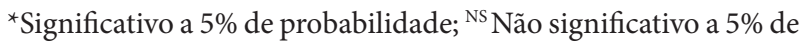
probabilidade pelo teste de Tukey.

Tabela 2 - Média das densidades do solo nas duas camadas, em ambos os rastros.

Table 2 - Mean density of soil in the two layers in both tracks.

\begin{tabular}{lc}
\hline Camadas $(\mathrm{m})$ & Média das densidades do solo $\left(\mathrm{Mg} \mathrm{m}^{-3}\right)$ \\
\hline $0,00-0,05$ & $1,30 \mathrm{a}^{1}$ \\
$0,10-0,15$ & $1,22 \mathrm{~b}$
\end{tabular}

${ }^{1}$ Letras iguais não diferem entre si ao nível de $5 \%$ de probabilidade pelo teste de Tukey.
Na análise da variável número de passadas, apresentada na Figura 2, o aumento da densidade do solo até a passada 5 foi de $16,24 \%$ em relação a condição sem tráfego, sendo de $1,36 \mathrm{Mg} \mathrm{m}^{-3}$ e $1,17 \mathrm{Mg} \mathrm{m}^{-3}$, respectivamente.

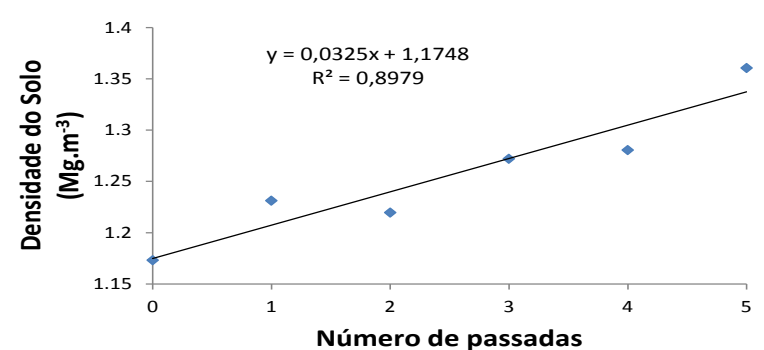

Figura 2 - Densidade do solo média das duas camadas e dos dois rastros em função do número de passadas. Média de 10 repetições.

Figure 2 - Soil density mean, sum of values from the two layers and two tracks, in relation to the variable number of passes. Mean of 10 repeats.

Para os valores médios de densidade do solo encontrados nas duas camadas, em relação a interação rastros e número de passadas, o valor médio foi de $1,17 \mathrm{Mg} \cdot \mathrm{m}^{-3}$ na condição sem tráfego e $1,33 \mathrm{Mg} \cdot \mathrm{m}^{-3}$ no rastro dos pneus para 5 passadas do Skidder (Figura 3). $\mathrm{O}$ aumento da densidade do solo foi praticamente linear, havendo aumento de 14,53\% na densidade do solo, ocorrendo a alteração da relação massa/volume do solo, podendo afetar os fluxos de ar e água, conforme descreve Rosa (2007).

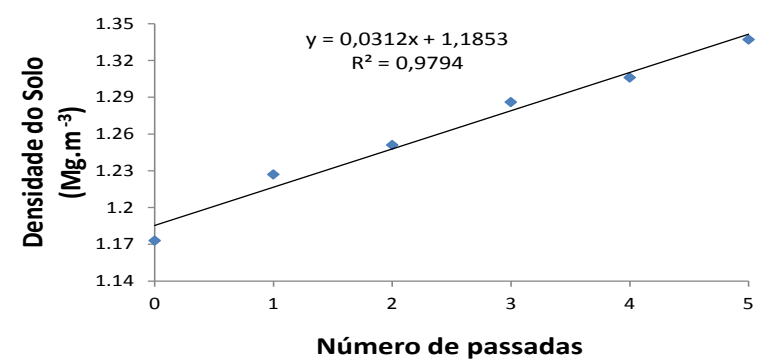

Figura 3 - Densidade do solo média das duas camadas e das diferentes passadas, considerando o rastro dos pneus. Média de 10 repetições.

Figure 3 - Soil density in the two layers and the number of passes considering the track of the tires. Mean of 10 repeats.

Cerne, Lavras, v. 20, n. 2, p. 199-208, abr./jun. 2014 
Os valores de densidades do solo do rastro dos fustes, apresentados na Figura 4, demonstram aumento da compactação na passada 1 , valor de $1,24 \mathrm{Mg} \mathrm{m}^{-3}$, ocorrendo aumento de 5,98\% na densidade média do solo. Porém, na passada 2, a compactação foi de $1,19 \mathrm{Mg} \cdot \mathrm{m}^{-3}$, havendo um aumento de $1,71 \%$ em relação à condição sem tráfego. Para as passadas 3 e 4 , ocorreram os aumentos de densidade do solo de 7,69\% em relação à condição sem tráfego, 1,61\% em relação a passada 1 e 5,88 \% em relação a passada 2. Na passada 5, o valor da densidade do solo foi de $1,38 \mathrm{Mg} \mathrm{m}-3$, havendo aumento de $17,95 \%$ na densidade do solo média no rastro dos fustes (Figura 4).

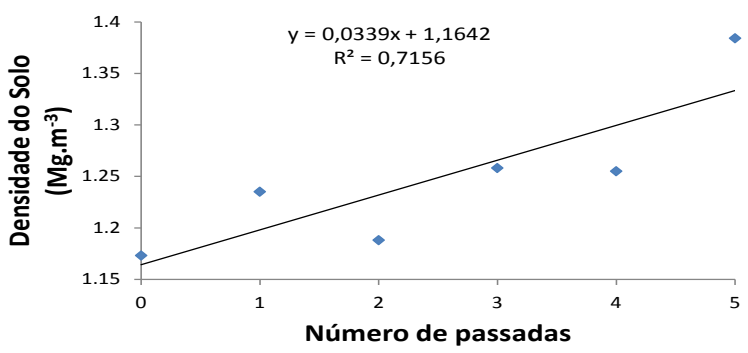

Figura 4 - Densidade do solo média nas duas camadas e das diferentes passadas, nos rastros dos fustes. Média de 10 repetições.

Figure 4 - Soil density mean in the two layers and the number of passes considering the tracks of the stems. Mean of 10 repeatitions.

Na camada de 0,00-0,05 m, na passada 1 a densidade do solo média para os dois rastros foi de $1,27 \mathrm{mg} . \mathrm{m}^{-3}$, para a interação camadas e número de passadas, apresentando aumento de $8,55 \%$ na densidade do solo em relação a condição sem tráfego. Na passada 2 o valor da densidade do solo diminuiu para 1,23 $\mathrm{mg} \mathrm{m}^{-3}$ Posteriormente ocorreu aumento progressivo da densidade do solo a cada passada, sendo o maior valor observado na camada entre $0,00 \mathrm{e}$ 0,05 m (Figura 5).

Para a camada de 0,10-0,15 m (Figura 6), as densidades do solo médias foram menores do que na camada de 0,00-0,05 m. Após 5 passadas o valor da densidade do solo foi igual de $1,30 \mathrm{Mg} \mathrm{m}^{-3}$ na camada de $0,10-0,15 \mathrm{~m}$, no entanto, na camada de $0,00-0,05 \mathrm{~m}$ observou-se valores de densidade do solo semelhante na passada 3 com valor igual a de $1,31 \mathrm{Mg} \mathrm{m}^{-3}$. Estes dados confirmam a avaliação realizada na Tabela 2 , que descreve a camada de 0,00-0,05 $\mathrm{m}$ como aquela que sofre maior influência da compactação pelo tráfego, concordando com
Håkansson (2005) o qual observou maior compactação na camada superficial.

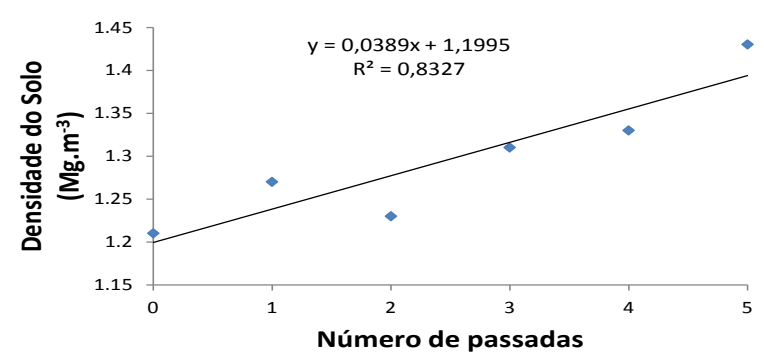

Figura 5 - Densidades do solo média na camada de 0,00-0,05 $\mathrm{m}$, da interação camadas e número de passadas. Média de 10 repetições.

Figure 5 - Density of the soil mean in layer 0.00 to $0.05 \mathrm{~m}$, and the relationship between layers and number of passes in the layer. Mean of 10 repeatitions.

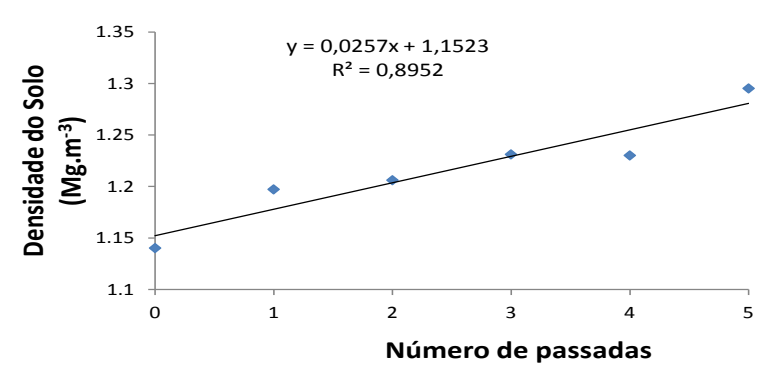

Figura 6 - Densidades do solo média na camada de 0,10-0,15 $\mathrm{m}$, da interação camadas e número de passadas. Média de 10 repetições.

Figure 6 - Density of the soil mean in layer 0.10 to $0.15 \mathrm{~m}$, and the relationship between layers and number of passes in the layer. Mean of 10 repeatitions.

O menor teor de água do solo (40\%) foi encontrado na passada 5 do rastro dos pneus (Tabela 3). Portanto, houve correlação com o valor de densidade do solo que foi $1,38 \mathrm{Mg} \mathrm{m}^{-3}$, sendo que na passada 5 foi onde ocorreram os maiores valores de compactação do experimento. Estes dados são justificados pelo ensaio de Proctor normal (Figura 7), onde o ponto máximo de compactação foi $33 \%$ de teor de água, valor menor ao da passada 5, no entanto, relativamente próximo do menor teor de água do experimento. Conforme ocorre o aumento do teor de água no solo, haverá a tendência de minimização do incremento da compactação, pois quanto maior a umidade do solo menor será a sua compressão, devido a água não sofrer deformação pela aplicação de forças sobre o solo. 
Para o rastro dos fustes, o menor teor de água do solo (41\%), foi encontrado na passada 5 , na camada de 0,10 a $0,20 \mathrm{~m}$, onde foi próxima a encontrada na camada de $0,00-0,10 \mathrm{~m}$, valor igual a $42 \%$ na camada superficial, no qual ocorreu a maior compactação do estudo (Tabela 4). Para condições de solo úmido, estes dados corroboram com Severiano et al. (2010), os quais citaram que os impactos das operações de colheita mecanizada no Cambissolo Háplico (CX) foram sempre inferiores aos observados no Latossolo Vermelho Amarelo (LVA), quando realizadas na época de maior pluviosidade. Neste estudo, a compactação no LVA foi adicional e crítica às funções edáficas em $100 \%$ das amostras e para o CX a limitação ocorreu em apenas $17 \%$ dos pontos.

Tabela 3 - Valores médios dos teores de água no solo (U) e de densidades do solo (Ds), no rastro dos pneus.

Table 3 - Mean values of soil moisture $(U)$ and the density of soil (Ds) in the track of the tires.

\begin{tabular}{lccccccc} 
& & \multicolumn{6}{c}{ Número de passadas do Skidder } \\
Camadas (m) & Sem tráfego & 1 & 2 & 3 & 4 & 5 \\
\cline { 3 - 7 } & & \multicolumn{6}{c}{$0-0,05 \mathrm{~m}$} \\
\hline $\mathrm{U}(\%)$ & 44 & 46 & 50 & 42 & 42 & 40 \\
$\mathrm{Ds}\left(\mathrm{Mg} \mathrm{m}^{-3}\right)$ & 1,21 & 1,27 & 1,27 & 1,32 & 1,36 & 1,38 \\
\hline \multicolumn{7}{c}{$0,10-0,15 \mathrm{~m}$} \\
\hline $\mathrm{U}(\%)$ & 52 & 50 & 53 & 47 & 45 & 43 \\
$\mathrm{Ds}\left(\mathrm{Mg} \mathrm{m}^{-3}\right)$ & 1,14 & 1,19 & 1,24 & 1,25 & 1,26 & 1,29 \\
\hline
\end{tabular}

Tabela 4 - Valores médios dos teores de água no solo (U) e de densidades do solo (Ds), no rastro dos fustes.

Table 4 - Mean values of soil moisture (U) and the density of soil (Ds) in the track of the stems.

Número de passadas do Skidder

\begin{tabular}{lcccccc} 
Camadas $(\mathrm{m})$ & Sem tráfego & 1 & 2 & 3 & 4 & 5 \\
\cline { 3 - 7 } & & \multicolumn{5}{c}{$0-0,05 \mathrm{~m}$} \\
\hline $\mathrm{U}(\%)$ & 44 & 46 & 50 & 50 & 42 & 42 \\
$\mathrm{Ds}\left(\mathrm{Mg} \mathrm{m}^{-3}\right)$ & 1,21 & 1,26 & 1,20 & 1,30 & 1,31 & 1,47 \\
\hline \multicolumn{7}{c}{$0,10-0,15 \mathrm{~m}$} \\
\hline $\mathrm{U}(\%)$ & 51 & 47 & 51 & 52 & 47 & 41 \\
$\mathrm{Ds}\left(\mathrm{Mg} \mathrm{m}^{-3}\right)$ & 1,14 & 1,21 & 1,18 & 1,21 & 1,20 & 1,30 \\
\hline
\end{tabular}

Os teores de água encontrados no experimento foram superiores ao valor da umidade ótima de compactação encontrado pelo teste de Proctor normal (Figura 7), que foi igual a $33 \%$. Os teores de água da área experimental variaram de $40 \%$ na camada de $0,00-0,10 \mathrm{~m}$ da passada 5 até $53 \%$ na camada de $0,10-0,20 \mathrm{~m}$ da passada 2 , ambos no rastro dos pneus (Tabela 3). Portanto, ocorrerá menor compactação do que poderia ocorrer se o teor de água estivesse em torno de 33\%, concordando com Santos et al. (2005) os quais explicaram que o Cambissolo tem maior capacidade de suporte devido ao maior ajuste entre e dentro dos agregados em formato de blocos com grau de coesão de moderado a forte.

O solo estava com alto teor de água da testemunha até a passada 5 , pois as chuvas ocorreram na semana anterior à execução do projeto, e do dia 02 para o dia 03 ocorreu uma chuva leve (garoa) sem o registro de seu volume, porém com pouca influencia no teor de água do solo. Devido à granulometria do solo ser siltosa, o solo apresenta plasticidade alta e a deformação do mesmo é menor em relação a outras classes de solo, quando comparados com os teores de água presente no experimento.

Os valores granulométricos encontrados foram os seguintes: $283 \mathrm{~g} \mathrm{~kg}^{-1}$ de argila, $670 \mathrm{~g} \mathrm{~kg}^{-1}$ de silte e $47 \mathrm{~g} \mathrm{~kg}^{-1}$ de areia. Para o valor de argila encontrada, pode-se considerar que o valor de densidade máxima não ultrapassou o nível considerado crítico ao desenvolvimento de plantas para solos com teor de argila de aproximadamente $200 \mathrm{~g} \mathrm{~kg}^{-1}$. O valor limite de densidade prejudicial às plantas é de 1,74 $\mathrm{Mg} \mathrm{m}^{-3}$ (REICHERT et al., 2009), sendo que no experimento o maior valor foi de $1,47 \mathrm{Mg} \cdot \mathrm{m}^{-3}$ no rastro dos fustes da passada 5 e camada de $0,00-0,05 \mathrm{~m}$, permanecendo abaixo deste limite.

Para o Cambissolo estudado, a maior compactação nos rastros ocorreram com os menores teores de água do experimento, sendo de $40 \%$ para o rastro dos pneus (Tabela 3) e $42 \%$ para o rastro dos fustes (Tabela 4), com

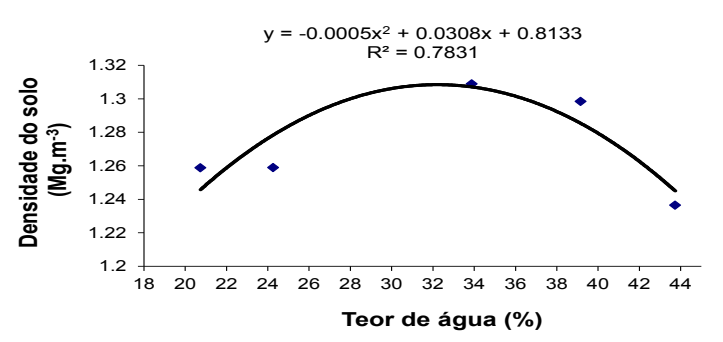

Figura 7 - Curva de compactação do Cambissolo Háplico.

Figure 7 - Compaction curve of the Inceptisol.

Cerne, Lavras, v. 20, n. 2, p. 199-208, abr./jun. 2014 
densidades de 1,38 e 1,47 $\mathrm{Mg} \mathrm{m}^{-3}$, respectivamente. Estes valores foram encontrados na passada 5 da camada de 0,00-0,10 m, que sofre maior influencia do tráfego do Skidder e dos fustes.

\section{CONCLUSÕES}

A camada superficial, entre 0,00 e $0,05 \mathrm{~m}$, sofreu maior influência do tráfego do Skidder e do arraste dos fustes, sendo que o rastro dos fustes compactou mais o solo do que o rastro dos pneus do Skidder;

O tráfego do Skidder e arraste dos fustes promoveram compactação do solo, onde para as passadas (tratamentos) houve diferença significativa nos valores encontrados.

O teor de água influenciou a compactação, sendo que a maior porcentagem de aumento ocorreu na passada 5 , onde o solo apresentou os menores teores de água durante o experimento.

\section{REFERÊNCIAS}

ANDRADE, S. C.; SOUZA, A. P.; SILVA, E.; NASCIMENTO, A. G.; MACHADO, C. C.; LEITE, H. G.; MINETTI, L. J. Análise dos efeitos da compactação do solo sobre a regeneração das cepas de eucalipto.

Revista Árvore, Viçosa, v. 24, p. 261-268, 2000.

DIAS JUNIOR, M. S.; LEITE, F. P.; LASMAR JÚNIOR, E.; ARAÚJO JUNIOR, C. F. Traffic effects on the soil preconsolidation pressure due to eucalyptus harvest operations. Scientia Agricola, Piracicaba, v. 62, n. 3, p. 248-255, 2005.

DIAS JUNIOR, M. S.; SILVA, A. R.; FONSECA, S.; LEITE, F. P. Método alternativo de avaliação da pressão de preconsolidação por meio de um penetrômetro.

Revista Brasileira de Ciência do Solo, Viçosa, v. 28, p. 805-810, 2004.

EMPRESA BRASILEIRA DE PESQUISA AGROPECUÁRIA. Manual de métodos de análises de solo. 2. ed. Rio de Janeiro: Ministério da Agricultura e do Abastecimento, 1997. 212 p.

EMPRESA BRASILEIRA DE PESQUISA AGROPECUÁRIA. Centro Nacional e Pesquisa em Solos. Sistema brasileiro de classificação de solos. Brasília, 2006. 306 p.

HÅKANSSON, I. Machinery-induced compaction of arable soils: incidence, consequences, counter-

Cerne, Lavras, v. 20, n. 2, p. 199-208, abr./jun. 2014 measures. Uppsala: Department of Soil Sciences, Division of Soil Management, 2005. 153 p.

HANZA, M. A.; ANDERSON, W. K. Soil compaction in cropping systems a review of the nature, causes and possible solutions. Soil \& Tillage Research, Amsterdam, v. 82, n. 2, p. 121-145, 2005.

IEZZI, G.; DOLCE, O.; TEIXEIRA, J. C.; MACHADO, N. J.; GOULART, M. C.; CASTRO, L. R. da S. ; MACHADO, A. dos S. Matemática. São Paulo: Atual, 1978. 325p.

INSTITUTO DE PESQUISAS TECNOLÓGICAS DO ESTADO DE SÃO PAULO. Mapa geológico do Estado de São Paulo. São Paulo, 1981. v. 1, 69 p. (Publicação IPT 1184). Escala 1:500.000.

KAISER, D. R.; REINERT, D. J.; REICHERT, J. M.; COLLARES, G. L.; KUNZ, M. Intervalo hídrico ótimo no perfil explorado pelas raízes de feijoeiro em um Latossolo sob diferentes níveis de compactação. Revista Brasileira de Ciência do Solo, Viçosa, v. 33, p. 845$855,2009$.

KÖPPEN, W. Die klimate der Erde. Berlin: W. Guyter, 1923. $369 \mathrm{p}$

KRÜMMELBEIN, J.; PETH, S.; HORN, R. Determination of pre-compression stress of a variously grazed steppe soil under static and cyclic loading. Soil and Tillage Research, Amsterdam, v. 99, n. 2, p. 139148, 2008.

LOCKABY, B. G.; VIDRINE, C. G. Effect of logging equipment traffic on soil density and growth and survival of young loblolly pine. Southern Journal of Applied Forestry, Washington, v. 8, n. 2, p. 109-112, 1984.

MARCHÃO, R. L.; BALBINO, L. C.; SILVA, E. M. da; SANTOS JUNIOR, J. de D. G. dos; SÁ, M. A. C. de; VILELA, L.; BECQUER, T. Qualidade física de um Latossolo Vermelho sob sistemas de integração lavoura-pecuária no Cerrado. Pesquisa Agropecuária Brasileira, Brasília, v. 42, n. 6, p. 873-882, jun. 2007.

MORAES, M. T.; DEBIASI, H.; FRANCHINI, J. C.; SILVA, V. R. Propriedades físicas do solo sob diferentes níveis de compactação em um Latossolo Vermelho distroférrico. In: JORNADA ACADÊMICA DA EMBRAPA SOJA, 6., 2011, Londrina. Resumos 
Expandidos... Londrina: EMBRAPA Soja, 2011. p. 5155. (Documentos, 328).

PEREIRA, J. C. D.; HIGA, A. R.; SHIMIZU, J. Y.; HIGA, R. C. V. Comparação da qualidade da madeira de três procedências de Eucalyptus dunnii maiden, para fins energéticos. Boletim de Pesquisa Florestal, Colombo, n. 13, p. 9-16, 1986.

REICHERT, J. M.; SUZUKI, L. E. A. S.; REINERT, D. J.; HORN, R.; HAKANSSON, I. Reference bulk density and critical degree-of-compactness for no-till crop production in subtropical highly weathered soils. Soil and Tillage Research, Amsterdam, v. 102, n. 2, p. 242-254, 2009.

REICHERT, J. M.; REINERT, D. J.; SUZUKI, L. E. A. S.; HORN, R. Mecânica do solo. In: LIER, Q. J. van (Ed.). Física do solo. Viçosa, MG: Sociedade Brasileira de Ciência do Solo, 2010. p. 29-102.

REICHERT, J. M.; SUZUKI, L. E. A. S.; REINERT, D. J. Compactação do solo em sistemas agropecuários e florestais: identificação, efeitos, limites críticos e mitigação. In: CERETTA, C. A.; SILVA, L. S.; REICHERT, J. M. (Ed.). Tópicos em ciência do solo. Viçosa, MG: Sociedade Brasileira de Ciência do Solo, 2007. v. 5, p. 49-134.

ROSA, D. P. Comportamento dinâmico e mecânico do solo sob níveis diferenciados de escarificação e compactação. 2007. 112 f. Dissertação (Mestrado em Engenharia Agrícola) - Universidade Federal de Santa Maria, Santa Maria, 2007.

SANTOS, R. D.; LEMOS, R. C.; SANTOS, U. G.; KER, J. C.; ANJOS, L. H. C. Manual de descrição e coleta de solo no campo. 5. ed. Viçosa, MG: Sociedade Brasileira de Ciência do Solo, 2005. 92 p.

SECCO, D.; REINERT, D. J.; REICHERT, J. M.; ROS, C. Produtividade de soja e propriedades físicas de um Latossolo submetido a sistemas de manejo e compactação. Revista Brasileira de Ciência do Solo, Viçosa, v. 28, p. 797-804, 2004.

SEIXAS, F.; SOUZA, C. R. Avaliação e efeito da compactação do solo devido à frequência de tráfego na produção de madeira de eucalipto. Revista Árvore, Viçosa, v. 31, n. 6, p. 1047-1052, nov./dez. 2007.

SEVERIANO, E. C.; OLIVEIRA, G. C.; DIAS

JÚNIOR, M. S.; CASTRO, M. B.; OLIVEIRA, L. F.
C.; COSTA, K. A. P. Compactação de solos cultivados com cana-de-açúcar: I., modelagem e quantificação da compactação adicional após as operações de colheita. Engenharia Agrícola, Jaboticabal, v. 30, n. 3, p. 404$413,2010$.

SILVA, R. B.; DIAS JUNIOR, M. S.; SILVA, F. A. M.; FOLE, S. M. O tráfego de máquinas agrícolas e as propriedades físicas, hídricas e mecânicas de um Latossolo dos cerrados. Revista Brasileira de Ciência do Solo, Viçosa, v. 27, p. 973-983, 2003.

STANCATI, G.; NOGUEIRA, J. B.; VILLAR, O. M. Compactação do solo. In: Ensaios de laboratório em mecânica dos solos. São Paulo: USP, 1981. p. 81-93.

SUZUKI, L. E. A. S.; REICHERT, J. M.; REINERT, D. J.; LIMA, C. L. R. de; Grau de compactação, propriedades físicas e rendimento de culturas em Latossolo e Argissolo. Pesquisa Agropecuária Brasileira, Brasília, v. 42, n. 8, p. 1159-1167, 2007.

SUZUKI, L. E. A. S.; REINERT, D. J.; REICHERT, J. M.; LIMA, C. L. R. de. Estimativa da susceptibilidade à compactação e do suporte de carga do solo com base em propriedades físicas de solos do Rio Grande do Sul. Revista Brasileira de Ciência do Solo, Viçosa, v. 32, p. 963-973, 2008.

VENTURA, A. Problemas técnicos da silvicultura paulista. Silvicultura São Paulo, São Paulo, v. 3, p. 61-80, 1964.

Recebido: 04 de abril de 2011; aceito: 17 de janeiro de 2014.

Cerne, Lavras, v. 20, n. 2, p. 199-208, abr./jun. 2014 
